\title{
The "First 1,000 Days+" as Key Contributor to the Double Burden of Malnutrition
}

\author{
Daniel Hoffman ${ }^{a}$ Maaike Arts ${ }^{b}$ France Bégin ${ }^{b}$ \\ aDepartment of Nutritional Sciences, Program in International Nutrition, New Jersey Institute for Food, Nutrition, \\ and Health, Center for Childhood Nutrition Research, Rutgers, the State University of New Jersey, New Brunswick, \\ NJ, USA; b Nutrition Section, Programme Division, United Nations Children's Fund (UNICEF), New York, NY, USA
}

\author{
Keywords \\ Breastfeeding · Complementary feeding · Growth · Double \\ burden · Malnutrition
}

\begin{abstract}
Growth from conception through age 2 years, the "First 1,000 days," is important for long-term health of the growing fetus and child and is influenced by several factors including breastfeeding and complementary feeding. Low- and middle-income countries face a complicated array of factors that influence healthy growth, ranging from high food insecurity, poor sanitation, limited prenatal or neonatal care, and high levels of poverty that exacerbate the "vicious cycle" associated with intergenerational promotion of growth retardation. It is now well recognized that the period prior to conception, both maternal and paternal health and diet, play an important role in fetal development, giving rise to the concept of the "First 1,000 Days+". Breastfeeding and complementary feeding practices can be improved through a combination of interventions such as baby-friendly hospitals, regulations for marketing of foods and beverages to children, adequate counseling and support, and sound social and behavior change communication, but continued research is warranted to make such programs more universal and fully effective. Thus, improving the overall understanding of factors that influence growth, such as improved breastfeeding and age-appropriate and adequate complementary feeding, is critical to reducing the global prevalence of the double burden of malnutrition.
\end{abstract}

(c) International Atomic Energy Agency 2019 Published by S. Karger AG, Basel

\section{The "First 1,000 Days+" and the Double Burden of Malnutrition}

Fetal growth is characterized by rapid cell division and differentiation. As tissues and organ systems grow and develop, the need for essential nutrients and energy to support the growth increases. Thus, improper nutrient availability or delivery threatens healthy growth. The preand periconceptual period has also been found to be a factor that influences fetal growth [1] and this time period, the first 1,000 days+, has a significant impact on growth and adult health. Therefore, to fully understand how to prevent or reverse the double burden of malnutrition (DBM), it is important to discuss all aspects of the first 1,000 days+, beginning with the preconception period through a child's first 1,000 days up to age 2 .

\section{Preconception and Pregnancy}

Paternal and maternal body composition and diet influence the first generation of offspring and may have an influence on the second generation as well [2]. In a study of grandpaternal obesity, the second-generation offspring of obese mice showed defects in lipid and glucose metabolism when fed a high fat diet [1]. It has also been found that maternal

The article is part of the Proceedings of the International Symposium on Understanding the Double Burden of Malnutrition for Effective Interventions organized by the International Atomic Energy Agency (IAEA) in cooperation with United Nations Children's Fund (UNICEF) and World Health Organization (WHO) (10-13 December 2018, Vienna, Austria).

Daniel Hoffman

Department of Nutritional Sciences, Program in International Nutrition Rutgers, the State University of New Jersey, New Jersey Institute for Food, Nutrition, and Health, 61 Dudley Road, New Brunswick, NJ 08901 (USA)

E-Maildhoffman@sebs.rutgers.edu 
body composition was the most significant predictor of fetal growth [3]. Moreover, siblings born during or after the Dutch Famine Winter had epigenetic differences in genes associated with chronic diseases, depending on the period of intrauterine famine exposure [4]. These studies suggest that preventing the DBM not only begins with the health of the parents but also has significant implications for the growth of the child. Innovative strategies to improve the health of men and women in low- and middle-income countries (LMICs) is clearly needed to effectively address the DBM. Such strategies would have to be broad and address the preconception health of both men and women, such as improved community-level access to nutrient dense foods, nutrition education for adolescents, but most important include improvements in social, income, and health-care inequalities $[5,6]$.

\section{Breastfeeding and the DBM}

One of the most important infant feeding practices to prevent the DBM is breastfeeding. Breastfeeding is essential for healthy growth and development [7], protects children against infections, overweight, and protects mothers from certain types of cancer and type 2 diabetes. Suboptimal breastfeeding is related to over 800,000 deaths in children under 5 years of age and 20,000 maternal deaths per year [8] with estimated economic losses at USD 302 billion per year [7].

Breastfeeding rates are far from optimal. In LMICs, less than half of all new-borns initiate breastfeeding in the first hour of life, only $41 \%$ of infants under 6 months of age are exclusively breastfed, and $45 \%$ of 2 -year olds are breastfeed [9]. This situation may be explained by various factors. In 2014, the global sales of breastmilk substitutes were almost USD 45 billion [7], and the marketing of breastmilk substitutes negatively impacts breastfeeding practices [10]. Other factors include inadequate support for breastfeeding in health facilities, communities, families, and the workplace. Yet, every dollar invested in breastfeeding brings USD 35 in economic returns [11].

At the 2018 IAEA/UNICEF/WHO symposium on the DBM, Dr. Nigel Rollins outlined factors that create barriers to exclusive breastfeeding around the globe [12] and noted that there is a dearth of environments that support breastfeeding at school, work, or home. More important, there is a lack of collective responsibility for low rates of breastfeeding, and the sole responsibility of breastfeeding is often delegated to the woman. Substandard science is used in the development of policies and claims for breastmilk substitutes often go unchallenged. As well, nutrition and health professionals often do not hold institutions and governments accountable for breastfeeding practices considering the inadequate regulation of the marketing of breastmilk substitutes.

\section{Complementary Feeding and the DBM}

During the first year of life, lean body mass nearly doubles, yet the energy provided from breastmilk remains constant and the gap in energy needs versus supply is met by the introduction of complementary foods, making it essential for healthy growth. When complementary foods are introduced after 6 months of age, energy and nutrient requirements are not met and growth either slows or ceases [13]. While delayed introduction of complementary feeding has been associated with a greater risk of overweight in life $[14,15]$, the evidence is not conclusive $[16,17]$. Nonetheless, to prevent the DBM, it is necessary that parents and caregivers understand the importance of introducing appropriate foods at the right time with continued breastfeeding. In particular, complementary foods need to be introduced from 6 months of age, provided with an age-appropriate frequency and amount and in a responsive manner, safely prepared and stored, of good quality (diverse, with an adequate micronutrient and energy content and a low anti-nutrient content), and continued during and after illness [13]. However, among LMICs, only $25 \%$ of children 6-23 months received foods from the minimum number of food groups that is recommended for their age, and nearly $1 / 3$ of children aged 6-8 months did not receive complementary foods [9].

Programs to promote complementary foods have been found to be somewhat effective, but challenges remain to make them fully effective [18]. Understanding risk factors and barriers to adequate complementary feeding, conducting situation analysis and formative research to inform strategies and interventions to put in place, having good monitoring and evaluation systems in place and sufficient resources are key elements to make programs more effective to promote adequate complementary feeding [18]. Also, many programs focus on stunting, the most severe form of growth retardation, as the primary outcome studied. Yet, a number of successes can be claimed for programs that do not necessarily influence stunting, such as improved iron status, increased maternal empowerment or education, and so on. Thus, it is important for evaluations to focus on changes in growth and other areas of interest rather than a single programmatic cutoff that may be influenced by a number of competing factors. 


\section{Potential Interventions to Improve Nutrition in the "First 1,000 Days"}

There are a number of avenues through which improved fetal growth and child health may be influenced. Aside from poverty reduction and improved diet quality for adolescents and adults who may become parents, breastfeeding and complementary feeding remain the primary drivers of child growth and health. Breastfeeding practices can be improved by providing adequate support via different delivery platforms, the community, and the home. A large review of the evidence found that combining interventions via different delivery platforms improved exclusive breastfeeding by $79 \%$ with a doubling of the effect when combining health system and the community [19]. As well, regulations for the marketing of breastmilk substitutes and for maternity protection are crucial to ensure optimal breastfeeding practices $[10,20]$. Other avenues to improve breastfeeding practices include implementing the actions of the Baby-friendly Hospital Initiative (WHO and UNICEF 2018) [21] and adherence to the 10 Steps [22]. Recently, UNICEF and WHO established the Global Breastfeeding Collective $[23,24]$ with 7 policy actions that advocate for improved breastfeeding practices at the global level, including increased funding, implementing the International Code of Marketing of Breastmilk Substitutes, maternity protection regulations and the BFHI's 10 Steps, and strengthening monitoring systems to track progress.

For designing a set of comprehensive actions to improve complementary feeding, countries are recommended to conduct barrier and bottleneck analyses, as used by UNICEF, government counterparts, and partners in a range of settings and countries, to assess the main determinants of effective coverage or optimal practices for selected interventions [25]. Quantitative and qualitative data are combined to characterize the environment (e.g., social norms, policies, and budget), supply- and servicesrelated factors (e.g., availability of materials and access to services), and demand-related factors (e.g., financial, social, and cultural factors) [26]. This approach was applied in Ethiopia for complementary feeding and brought together stakeholders to review and prioritize bottlenecks and potential solutions. The results showed that food taboos, weak multisectoral engagements, limited father/ male involvement, limited availability of fruits and vegetables, and poor knowledge and awareness from caregivers were identified as key bottlenecks to proper complementary feeding. The involvement of the stakeholders helped build consensus and prioritize solutions and strategies that were felt to be manageable by the stakeholders.
Bottleneck analysis should be part of an ongoing process to improve programs and coverage by making adjustments as needed. Apart from infant feeding practices, it is also important to emphasize the importance of parental health for the prevention of the DBM given that that the health and diet of parents, even prior to conception of a child, has a profound influence on the health of their child during gestation and perhaps for the life of their child.

\section{Conclusions}

As the DBM continues to increase across the world, particularly in LMICs, addressing proper nutritional practices during pregnancy and early childhood remains a high priority. Determining how best to support and normalize such behaviors depends on availability and access to nutrient-rich foods, access to education, empowerment of women to control household resources, and greater father's involvement in child care. As well, the health and nutrition community needs to advance policies that promote healthy and sustainable diets, starting with breastfeeding, and investments in the implementation and scale up of evidence-informed interventions to prevent the DBM. It is also important to emphasize that the health and diet of parents, even prior to conception of a child, have a profound influence on the health of their child during gestation and, perhaps, for life. Finally, innovative and interdisciplinary research and interventions with responsible public-private partnerships have key roles to play to ensure that such knowledge and policies function in a coordinated fashion to reduce the DBM.

\section{Acknowledgments}

The authors would like to thank Nigel Rollins for his contribution on breastfeeding and Cornelia Loechl, Theodora Mouratidou, and Pernille Kaestel for their critical reviews of the manuscript.

\section{Statement of Ethics}

The authors have no ethical conflicts to disclose for this review because there were no humans or animals involved directly.

\section{Disclosure Statement}

The authors have no conflicts of interest to declare. 


\section{Funding Sources}

No external funding source contributed to the writing of this paper.

Open access provided with a grant from the International Atomic Energy Agency.

\section{Author Contributions}

All authors conceptualized the overall design of the manuscript and contributed to writing of the final manuscript. All authors read and approved the draft.

\section{Disclaimer}

The statements, opinions and data contained in this publication are solely those of the individual authors and contributors, not of the publishers and the editor(s), and do not necessarily reflect the views of the cooperating organizations, IAEA, UNICEF and WHO. The use of particular designations of countries or territories does not imply any judgement by the cooperating organizations, as to the legal status of such countries or territories, of their authorities and institutions or of the delimitation of their boundaries. The mention of names of specific companies or products (whether or not indicated as registered) does not imply any intention to infringe proprietary rights, nor should it be construed as an endorsement or recommendation on the part of the cooperating organizations.

\section{References}

1 Cropley JE, Eaton SA, Aiken A, Young PE, Giannoulatou E, Ho JW, et al. Male-lineage transmission of an acquired metabolic phenotype induced by grand-paternal obesity. Mol Metab. 2016 Jun;5(8):699-708.

2 Sanchez-Garrido MA, Ruiz-Pino F, Velasco I, Barroso A, Fernandois D, Heras V, et al. Intergenerational Influence of Paternal Obesity on Metabolic and Reproductive Health Parameters of the Offspring: Male-Preferential Impact and Involvement of Kiss1-Mediated Pathways. Endocrinology. 2018 Feb;159(2): 1005-18.

3 Toro-Ramos T, Sichieri R, Hoffman DJ. Maternal fat mass at mid-pregnancy and birth weight in Brazilian women. Ann Hum Biol. 2016 May;43(3):212-8.

4 Tobi EW, Goeman JJ, Monajemi R, Gu H, Putter H, Zhang Y, et al. DNA methylation signatures link prenatal famine exposure to growth and metabolism. Nat Commun. 2014 Nov;5(1):5592.

5 Stephenson J, Heslehurst N, Hall J, Schoenaker DAJM, Hutchinson J, Cade JE, et al. Before the beginning: nutrition and lifestyle in the preconception period and its importance for future health. Lancet. 2018 May; 391(10132):1830-41.

6 Perez-Escamilla R, Bermudez O, Buccini GS, Kumanyika S, Lutter CK, Monsivais P, et al. Nutrition disparities and the global burden of malnutrition. BMJ. 2018 Jun;361:k2252.

7 Rollins NC, Bhandari N, Hajeebhoy N, Horton S, Lutter CK, Martines JC, et al.; Lancet Breastfeeding Series Group. Why invest, and what it will take to improve breastfeeding practices? Lancet. 2016 Jan;387(10017):491504.

8 Victora CG, Bahl R, Barros AJ, França GV, Horton S, Krasevec J, et al.; Lancet Breastfeeding Series Group. Breastfeeding in the 21st century: epidemiology, mechanisms, and lifelong effect. Lancet. 2016 Jan;387(10017):47590.

9 UNICEF. IYCF database [Internet]. Infant and Young Child Feeding. 2018. Available from: https://data.unicef.org/topic/nutrition/ infant-and-young-child-feeding/\#status.

10 Piwoz EG, Huffman SL. The Impact of Marketing of Breast-Milk Substitutes on WHORecommended Breastfeeding Practices. Food Nutr Bull. 2015 Dec;36(4):373-86.

11 Walters D, Eberwein J, Sullivan L, Shekar M. Reaching the global target for breastfeeding. In: Walters D, Eberwein J, Shekar M, editors. An investment framework for nutrition; Reaching the global targets for stunting, anemia, breastfeeding and wasting. Washington : World Bank Group; 2017.

12 Rollins NC. Breastfeeding: New knowledge and old failures. [Internet]. Rollins NInternational Symposium on Understanding the Double Burden of Malnutrition for Effective Interventions.; 2018 Dec 10; Vienna, Austria. Available from: https://bit.ly/2FA2bGB.

13 World Health Organization. Infant and young child feeding: model chapter for textbooks for medical students and allied health professionals. Geneva: World Health Organization; 2009.

14 Zheng JS, Liu H, Zhao YM, Li J, Chen Y, Zhu $\mathrm{S}$, et al. Complementary feeding and childhood adiposity in preschool-aged children in a large Chinese cohort. J Pediatr. 2015 Feb; 166(2):326-31.e2.

15 Morgen CS, Ängquist L, Baker JL, Andersen AN, Sørensen TI, Michaelsen KF. Breastfeeding and complementary feeding in relation to body mass index and overweight at ages 7 and $11 \mathrm{y}$ : a path analysis within the Danish National Birth Cohort. Am J Clin Nutr. 2018 Mar; 107(3):313-22.

16 Schack-Nielsen L, Sørensen TI, Mortensen EL, Michaelsen KF. Late introduction of complementary feeding, rather than duration of breastfeeding, may protect against adult overweight. Am J Clin Nutr. 2010 Mar;91(3):61927.

17 English LK, Obbagy JE, Wong YP, Butte NF, Dewey KG, Fox MK, et al. Timing of introduction of complementary foods and beverages and growth, size, and body composition: a systematic review. Am J Clin Nutr. 2019 Mar;109(Supplement_7):935S-955S.

18 Bégin F, Aguayo VM. First Foods: Why improving young children's diets matter. Matern Child Nutr. 2017 Oct;13 Suppl 2:e12528.

19 Sinha B, Chowdhury R, Sankar MJ, Martines J, Taneja S, Mazumder S, et al. Interventions to improve breastfeeding outcomes: a systematic review and meta-analysis. Acta Paediatr. 2015 Dec;104(467):114-34.

20 Navarro-Rosenblatt D, Garmendia ML. Maternity Leave and Its Impact on Breastfeeding: A Review of the Literature. Breastfeed Med. 2018 Nov;13(9):589-97.

21 Pérez-Escamilla R, Martinez JL, Segura-Pérez S. Impact of the Baby-friendly Hospital Initiative on breastfeeding and child health outcomes: a systematic review. Matern Child Nutr. 2016 Jul;12(3):402-17.

22 WHO. UNICEF. Implementation guidance: protecting, promoting and supporting breastfeeding in facilities providing maternity and newborn services - the revised Baby-friendly Hospital Initiative. Geneva: World Health Organization; 2018.

23 Arts M, Taqi I, Bégin F. Improving the early initiation of breastfeeding: the WHO-UNICEF Breastfeeding Advocacy Initiative. Breastfeed Med. 2017 Jul/Aug;12(6):326-7.

24 Bégin F, Lapping K, Clark D, Taqi I, Rudert C, Mathisen R, et al. Real-time evaluation can inform global and regional efforts to improve breastfeeding policies and programmes. Matern Child Nutr. 2019 Feb;15 Suppl 2:e12774.

25 Untoro J, Childs R, Bose I, Winichagoon P, Rudert C, Hall A, et al. Tools to improve planning, implementation, monitoring, and evaluation of complementary feeding programmes. Matern Child Nutr. 2017 Oct;13 Suppl 2:e12438.

26 Chopra M, Sharkey A, Dalmiya N, Anthony D, Binkin N.; UNICEF Equity in Child Survival, Health and Nutrition Analysis Team. Strategies to improve health coverage and narrow the equity gap in child survival, health, and nutrition. Lancet. 2012 Oct;380(9850):1331-40. 